\title{
A TEORIA CRÍTICA DOS SISTEMAS \\ DA ESCOLA DE FRANKFURT*
}

\author{
ANDREAS FISCHER-LESCANO \\ TRADUÇÃO DE RÚRION MELO
}

\section{RESUMO}

Apesar de seu ceticismo em relação à razão e à moralidade universais, a Teoria Crítica e a Teoria Crítica dos Sistemas compartilham alguns pressupostos básicos: (1) o uso de conceitos sistêmicos e institucionais, que transcendem as meras relações intersubjetivas graças à sua complexidade; (2) a idéia de que a vida social é marcada por paradoxos, antagonismos e antinomias fundamentais; (3) a estratégia de definir a justiça como uma fórmula contingente e transcendental; (4) o recurso à crítica imanente (e não externa, de fundo moral) como uma atitude de transcendência; (5) o objetivo de emancipação social (e não apenas política) em uma "associação de indivíduos livres" (Marx). O artigo enfoca esses paralelos e procura esboçar uma virada crítica da teoria dos sistemas autopoiéticos.

PALAVRAS-CHAVE: Teoria Crítica; teoria crítica dos sistemas; justiça; sociedade global; direito global

\section{ABSTRACT}

Besides their skepticism about universal reason and universal morality, the Frankfurt Schools of Critical Systems Theory and Critical Theory share basic assumptions: (1) the thinking in societal-systemic, institutional concepts, which transcend simple reciprocal relations by dint of their complexity; (2) the assumption that society is based on fundamental paradoxes, antagonisms, antinomies; (3) the strategy to conceptualize justice as a contingent and transcendental formula; (4) the form of immanent (and not morality-based, external) critique as an attitude of transcendence; (5) the aim of societal (and not only political) emancipation in an "association of free individuals" (Marx). The article focuses on those parallels and aims to conceptualize a critical turnaround of autopoietic systems theory.

KEYWORDS: Critical theory; critical system theory; justice; world society; global law

[*] Em comemoração aos 65 anos de Gunther Teubner.

[1] Hauke Brunkhorst esboçou cuidadosamente os paralelos entre a concepção de sociedade de Adorno e a da teoria dos sistemas; na verdade, ele próprio apresentou a possibilidade de uma reentrada da teoria crítica dos sistemas na Teoria Crítica.

[2] Habermas, Jürgen. "Theorie der Gesellschaft oder Sozialtechnologie?“. In: Habermas e Luhmann, N. Theorie der Gesellschaft oder Sozialtechnologie. Frankfurt a.M.: Suhrkamp, 1974.
Uma crítica do sistema, no sentido empregado por Adorno, épossivel apenas se dispomos de um conceito de sistema social. Brunkhorst, "Ästhetik als Gesellschaftskritik: Vier Fragen zu Adorno", p. $17^{1}$

É uma suposição comum a de que uma "teoria crítica dos sistemas" não existe. Diz-se que falta a toda teoria dos sistemas um ímpeto crítico-emancipatório; por ser meramente uma forma descritiva de investigação, ela representa a "forma suprema da consciência tecnocrática", a "apologia" do status quo, pois o preserva. Foi essa, pelo menos, a opinião que Jürgen Habermas ${ }^{2}$ defendeu em seu 
conhecido debate com Niklas Luhmann³. Esse tipo de caracterização fechou, por um longo tempo, a teoria crítica para a influência da teoria dos sistemas. Contudo, no que se segue, argumentarei que essa separação hoje em dia não é pertinente. De fato, há uma "teoria crítica dos sistemas" 4 . Essa teoria crítica dos sistemas pode filiar-se com os trabalhos da primeira geração de teóricos críticos da Teoria Crítica da Escola de Frankfurt que procura revelar o nexo entre as normatizações sistêmicas e a subjetividade - descrito por Adorno como uma reificação transsubjetiva e, justamente por isso, ao mesmo tempo como privação de poder 5 .

Desenvolvida principalmente por Gunther Teubner no terceiro andar da Faculdade de Ciências Jurídicas na Senckenberganlage 31, frente ao Instituto de Pesquisa Social em Frankfurt am Main, a teoria dos sistemas da sociedade mundial também é uma teoria crítica dos sistemas sociais. A teoria transcende uma mera descrição de problemas estruturais e submete as estruturas sociais a uma crítica que pode ser produtivamente apropriada de várias maneiras pelas atuais teorias pós-materiais ${ }^{6}$. Uma teoria crítica dos sistemas aborda as antinomias das estruturais sociais; ela realiza uma crítica imanente, em atitude não-conformista, abarcando igualmente o "olho maligno", tão caro à teoria crítica7. Dessa forma, a abordagem procura identificar e reforçar os processos sociais que podem conduzir à superação das ordens sociais reificadas.

Gostaria de esboçar a seguir os elos entre a teoria crítica dos sistemas e a Teoria Crítica. Além de seu ceticismo em relação à razão ou à moralidade universais, ambas as abordagens compartilham os seguintes princípios:

1. Pensar em termos de conceitos da teoria dos sistemas sociais e institucionais, que transcendem as relações intersubjetivas em função de sua complexidade.

2. A suposição de que a sociedade se baseia em paradoxos, antagonismos e antinomias fundamentais.

3. Aestratégia de conceber ajustiça como uma fórmula contingente e transcendente.

4. A crítica imanente (e não externa, baseada na moralidade) como forma, numa atitude de transcendência.

5. O objetivo da emancipação social (e não apenas política), pela constituição de uma "comunidade de indivíduos livres" (Marx).

Essas semelhanças, que explorarei separadamente, estão vinculadas ao desenvolvimento da teoria dos sistemas no spiritus locifrancofurtensis. Enquanto Niklas Luhmann preferiu, por assim dizer, se isolar confortavelmente com seu copo de champanhe em uma sala vip,
[3] A razão para o encontro entre ambos foi o fato de Luhmann ter se tornado professor substituto na cadeira de Adorno, em Frankfurt, em 1968/1969. Sobre a convergência de ambas as posições e afirmações sobre mais afinidades, ver Kjaer, Poul."Systems in context: on the outcome of the Habermas/LuhmannDebate". Ancilla Iuris, 2006,pp. 66ss.

[4] RudolfWiethölter criou o termo "teoria crítica dos sistemas" e defendeu a teoria crítica "sob condições sistêmicas". Ele introduziu o conceito em um seminário juntamente com Gunther Teubner e eu no final do verão de 2007 que tratava do "pluralismo constitucional na sociedade mundial".

[5] Cf. a reconstrução em Honneth, Axel. Pathologien der Vernunft: Geschichte und Gegenwart der Kritischen Theorie, Frankfurt a.M.: Suhrkamp, 2007, pp. 44ss.; e Zuidervaart, Lambert. Social philosophy after Adorno. Cambridge: UP, 2007, pp. 8ss.

[6] Cf., por exemplo, Jessop, Bob. "Zur Relevanz von Luhmanns Systemtheorie und von Laclau und Mouffes Diskursanalyse für die Weiterentwicklung der materialistischen Staatstheorie". In: Hirsch, J. E outros (eds.). Der Staat der Bürgerlichen Gesellschaft: Zum Staatsverständnis von Karl Marx. Baden-Baden: Nomos, 2008; Buckel, Sonja. Subjektivierung und Kohäsion. Weilerswist: Velbrück Wissenschaft, 2007, pp. 230ss.; Negri, Antonio. "Philosophy of law against sovereignty". European Journal of Legal Studies, 2008, pp. 1-11; Möller, K. "Global Assemblages im neuen Konstitutionalismus". Ancilla Iuris, 2008, pp. 44ss; Brunkhorst, Hauke. "Die Legitimationskrise der Weltgesellschaft". In:Albert, M.e Stichweh, R. (eds.). Weltstaat und Weltstaatlichkeit. Wiesbaden: VS, 2008; Blecher, Michael. Zu einer Ethik der Selbstreferenz oder: Theorie als Compassion. Berlim: Duncker und Humblot, 1991; Willke, Helmut. Stand und Kritik der neueren Grundrechtstheorie: Schritte zu einer normativen Systemtheorie. Berlim: Duncker und Humblot, 1975.

[7] Sobre a expressão "olho maligno" e o conceito tradicional de crítica, ver Demirović, Alex. Demokratie in der Wirtschaft. Münster: Westfälisches Dampfboot, 1999; ver também Honneth, Axel. "Gerechtigkeit im 
Vollzug". In: Pathologien der Vernunft: Geschichte und Gegenwart der Kritischen Theorie. Frankfurt a.M.: Suhrkamp, 2007a, pp. 57ss.

[8] Luhmann, Niklas. "Einige Probleme mit 'reflexivem Recht'”. Zeitschrift für Rechtssoziologie, 1985, p. 2.

\begin{abstract}
[9] "Nosso vôo precisa pairar por cima das nuvens, e precisamos contar com uma camada finíssima de nuvem. [...] Ocasionalmente, poderemos ver alguns reflexos abaixo [...] reflexos de um grande trecho de paisagem com o extintos vulcões do marxismo": Luhmann, Niklas. Social systems. Stanford: Stanford University Press, 1995, p. 1.
\end{abstract}

[10] Teubner, Gunther. "Dreiers Luhmann”. In: Alexy, R. (ed.). Integratives Verstehen: Zur Rechtsphilosophie Ralf Dreiers. Tübingen: Mohr/ Siebeck, 2005, p. 210; ver também Blecher. "Recht in Bewegung: Paradoxontologie, Recht und Soziale Bewegungen". Archiv für Rechts- und Sozialphilosophie, 2006, pp.449ss.

[11] “[...] essas relações petrificadas têm de ser forçadas a dançar ao cantarem para si mesmas suas próprias músicas!": Marx, K. "Critique of Hegel's philosophy of right: introduction" [1844]. In: Critique of Hegel's philosophy of right. ed. J. O'Malley. Cambridge: Cambridge University Press 1970 .

[12] Teubner. "Der Umgang mit Rechtsparadoxien: Derrida, Luhmann, Wiethölter". In: Joerges, Ch. e Teubner (eds.). Rechtsverfassungsrecht. Baden-Baden: Nomos, 2003, p. 31. Nesse contexto seminal, ver Wiethölter, Rudolf. "Begriffs- oder Interessenjurisprudenz". In: Lüderitz, A. e Schröder, G. (eds.). Internationales Privatrecht und Rechtsvergleichung im Ausgang des 20. Jahrhunderts: Festschrift für Gerhard Kegel. Frankfurt a.M: Metzner, 1977. refrescada por ar-condicionado, no $27^{\circ}$ andardo terraço de observação do "Grande Hotel Abismo", a teoria crítica dos sistemas trouxe sua perspectiva para o "lado certo". Enquanto Luhmann explica os nexos comunicativos pela própria comunicação, a teoria crítica dos sistemas revela as contingências e as controvérsias políticas envolvidas nessas interconexões, lendo, com intenções desconstrutivistas, a teoria a contrapelo. Enquanto Luhmann imuniza a teoria dos sistemas contra as exigências normativas que surgem da necessidade de adequação dos sistemas ao ambiente circundante, a teoria crítica dos sistemas é sensível às controvérsias em torno de concepções divergentes de ordens sociais "justas". Isso abre espaço para uma "virada normativa" da teoria dos sistemas, cuja complexidade teórica Luhmann apreciava, embora seus fundamentos normativo não tenham seduzido o observador de Bielefeld: Luhmann ${ }^{8}$ considerou o conceito de teoria crítica dos sistemas "sobrecarregado, com a intenção de criar uma síntese de teorias de inclinação 'crítica-emancipatória' com noções de 'dogmática reativa' e análises sociológicas do 'sistema jurídico'".

A teoria crítica dos sistemas leva o objeto voador não-tripulado de Niklas Luhmann e seu ponto de vista antinormativista de volta à terra depois de um vôo cego sobre as nuvens e os vulcões do marxismo?. Assim como na dialética hegeliana, para ela as contradições são o motor do desenvolvimento social; e ela deriva de algumas analogias, com a mesma intenção que o hegelianismo de esquerda, "das contradições reais, na tradição teórica de Marx. O paralelo é com o ato de pôr as coisas no lugarcerto: os paradoxos não existem no mundo ideal do espírito, mas na experiência real das sociedades altamente desenvolvidas" ${ }^{10}$.

Isso explicita a capacidade da teoria dos sistemas de descrever as condições funcionais da sociedade mundial, plenamente diferenciada, de revelar seus paradoxos e, assim, tornar-se um veículo de uma forma de crítica que transcende a abordagem sistêmica. Por isso a teoria crítica dos sistemas, assim como Karl Marx ${ }^{11}$, insiste que "os paradoxos reais colocam as relações sociais para dançar" ${ }^{\prime 2}$.

\section{TRANSSUBJETIVIDADE}

Essa definição, que soa altamente formal, pressupõe que a sociedade é uma entidade formada porseres humanos, que ela é humana, e que está diretamente em acordo com seus sujeitos; como se o "social" não fosse justamente a preponderância das relações sobre os indivíduos, os quais são seus produtos impotentes. Adorno, "Gesellschaft", p. 9

A teoria crítica dos sistemas da Escola de Frankfurt compartilha com a geração fundadora da Teoria Crítica a suposição básica da não-identidade entre indivíduos e sociedade. As condições sociais 
não são interpretadas como monologicamente subjetivas (como no imperativo categórico de Kant), tampouco como intersubjetivas, mas transsubjetivas.

Kant e seus seguidores da segunda geração da teoria crítica tentaram rearticular socialmente o complexo das instituições administrativas com o direito democraticamente legitimado ${ }^{13}$.

Essa posição incorpora a noção de Adorno da fuga do "mundo administrado", e com isso um kantismo radicalmente democrático, na figura de Ingeborg Maus, encontra a teoria social na tradição de Adorno. Segundo a perspectiva de Adorno, no entanto, essa postura é reformista, uma vez que toda tentativa de humanizar as instituições, "não importa o quão boas sejam as intenções, pode somente amortecer ou enfeitar a forma atual das contradições sociais, mas não aboli-las" ${ }^{14}$.O foco em uma concepção política das instituições, continua a acusação, implicaria que a alienação seria um problema cuja raiz estaria no sistema político, e que seria possível "racionalizar o irracional". Essa estratégia, no entanto, seria precisamente uma manifestação da fetichização das coletividades e das organizações, a qual precisa ser superada ${ }^{15}$.

Contra essa fetichização, a teoria crítica dos sistemas da Escola de Frankfurt busca realizar uma análise detalhada da sociedade de inspiração sistêmica e, ao mesmo tempo, procura por estratégias de desreificação. Seu ponto de partida comum são os processos de diferenciação social. Entre os autores clássicos da sociologia, vêm à mente Émile Durkheim e Talcott Parsons. O primeiro, a quem Adorno admirava apesar de todas as suas críticas, era superior ao positivismo mainstream, uma vez que jogou luz sobre os fenômenos de institucionalização e reificação sociais ${ }^{16}$. Quanto a Parsons, Adorno o critica por ter confundido psicologia e sociologia em sua tentativa de fundar, por meio da teoria dos sistemas, uma ciência humana unificada: tal abordagem seria incapaz de dar conta da divergência, ela própria socialmente condicionada, entre indivíduo e sociedade, assim como já ocorreria com as duas disciplinas.

Esse esquema totalizante e pedante de Parsons avaliou incorretamente que indivíduo e sociedade, apesar de não serem radicalmente diferentes, separaram-se historicamente ${ }^{17}$. Esseé exatamente o ponto em que a teoria moderna dos sistemas, no sentido que Luhmann lhe atribui, difere da teoria sistêmica de Parsons, e em que, como já fez Adorno, Luhmann introduz a diferença radical entre sistemas de consciência e sistemas sociais autopoiéticos. Assim como Adorno, Luhmann descreve a sociedade como um sistema auto-reprodutivo, como uma realidade social que a princípio se encontra fora do alcance das intenções práticas de seus atores. A teoria crítica dos sistemas, que considera que a existência independentemente de redes comunicativas implica a exclusão radical dos indivíduos da sociedade, refere-se a esse paralelo:
[13] Maus, Ingeborg. "Zur Theorie der Institutionalisierung bei Kant". In: Göhler, G. e outros (eds.). Politische Institutionen im gesellschaftlichen Umbruch. Opladen: Westdeutscher Verlag, 1990.

[14] Adorno, Theodor. "Individuum und Organisation". In: Gesammelte Schriften, Frankfurt a.M.: Suhrkamp, 2003b, vol. 8, p. 453 .

[15] Ibidem, p. 455 .

[16] Idem. "Einleitung zu Emile Dürkheim 'Soziologie und Philosophie'" [1967]. In: Gesammelte Schriften, op. cit., p. 250.

[17] Idem. "Einleitung zum Positivismusstreit in der deutschen Soziologie" [1969]. In: Gesammelte Schriften, op. cit., p. 297. Para crítica de Adorno a Parsons, ver também Ador. "Zum Verhältnis von Soziologie und Psychologie" [1968]. In: Gesammelte Schriften, op. cit., p. 18. 
[18] Teubner. "Die anonyme Matrix: $\mathrm{Zu}$ Menschenrechtsverletzungen durch 'private' transnationale Akteure". Der Staat, 2006, vol. 45, pp. 16187 , p. 168; com referência a Menke, Christoph. Spiegelungen der Gleichheit: Politische Philosophie nach Adorno und Derrida. Berlim: Akademie-Verlag, 2004.

[19] Luhmann. Recht der Gesellschaft. Frankfurt a.M.: Suhrkamp, 1993, pp.35ss.

[20] Adorno. "Über Marx und die Grundbegriffe der soziologischen Theorie. Seminarmitschriften". In: Backhaus, H.-G. (ed.). Dialektik der Wertform: Untersuchungen zur Marxschen Ökonomiekritik. Freiburg: Ça Ira, 1997 , p. 504.

[21] Luhmann. "Selbst-Thematisierungen des Gesellschaftssystems". In: SoziologischeAufklärung. Opladen:WestdeutscherVerlag, 2005, vol.2, p. 101.

[22] Marx.Capital[1867].Londres:Lawrence and Wishart, 1974, vol.1, cap.4.

[23] A esse respeito, ver Breuer. Stefan. "Adorno/Luhmann: Konvergenzen und Divergenzen von Kritischer Theorie und Systemtheorie". Leviathan, 1987, pp.91ss, p.103.

[24] Adorno. "Individuum und Organisation". In: Gesammelte Schriften, op.cit., p.361.

[25] Marx. "Theses On Feuerbach" [1845]. In: Marx e Engels, F. Selected works. Moscou: Progress Publishers, 1969 , vol. 1, tese 6 .

[26] Teubner. "Selbstsubversive Gerechtigkeit: Kontingenz- oder Transzendenzformel des Rechts?". Zeitschrift für Rechtssoziologie, 2008 , vol. 29, pp. 9-36, p.11.
Aqui a teoria dos sistemas retorna ao tema da alienação social tão caro à tradição da teoria sociale os adota de forma quase oportunista. Contatos clandestinos com teorias oficialmente inimigas, tais como os estudos de Foucaultsobre o poder disciplinar, a crítica de Agamben à exclusão social, a teoria de Lyotard dos discursos fechados e a noção de justiça de Derrida, são estabelecidos ${ }^{18}$.

Tal reformulação teórica evoca, naturalmente, a crítica humanista: quem não concebe a sociedade como uma comunidade de indivíduos embarca em reflexões sobre o inumano, age contra-intuitivamente e não está interessado no destino da humanidade. Diante de tais críticas, Adorno e Luhmann reagem basicamente do mesmo modo. Enquanto Luhmann ${ }^{19}$ se incomodava com o uso geralmente no singular da palavra "humano" pelos humanistas, o que indicaria uma inclinação pelo indivíduo, Adorno ${ }^{20}$ procurou interpretar a não-identidade fazendo referência ao materialismo histórico, segundo o qual a análise "do" indivíduo não era mais possível: "isso seria superficial em relação ao ser histórico".

Faz sentido que Luhmann ${ }^{21}$, em sua introdução ao conceito de auto-referência, declare preservar a noção de sociedade de Marx como conjunto de "sistemas sociais abstratos, categorizantes e tematizadores". Assim como Marx ${ }^{22}$, que entendia o valor econômico do capital "como uma substância independente, dotada de movimento e processo vital próprios, na qual dinheiro e mercadorias são meras formas", a teoria dos sistemas dá importância central ao conceito de auto-referência dos sistemas sociais ${ }^{23}$. Contudo, diferentemente de Marx e da teoria crítica, a teoria crítica dos sistemas admite uma multiplicidade de processos sociais auto-referentes. Nesse sentido, enquanto Adorno segue Marx ao favorecer um conceito monista de sistema e investiga os processos pelos quais, no interior de um sistema social singular, os indivíduos são forçados, até nas mais íntimas regulações, a "se subordinarem ao mecanismo social [...] e a se moldarem a ele por completo" 24 , os estudos da teoria dos sistemas se debruçam sobre a pluralidade de diferenciações internas do sistema social mundial. Não é apenas o indivíduo que é resultado do "conjunto das [...] relações sociais" 25 , como também a sociedade é o conjunto dos subsistemas sociais. Acima de tudo,é impossível entender a sociedade dando atenção meramente à ação individual:

Dada a policontextualidade, ou seja, a emergência de estruturas sociais intermediárias profundamente fragmentadas, e o distanciamento dos sistemas de interação entre si, não se podem compreender as organizações formais e os sistemas sociais com base apenas no conceito de interaçãa ${ }^{26}$. 
Em sua ênfase na diferenciação social mundial, nos sistemas, nas organizações e nos regimes funcionais globais, a teoria crítica dos sistemas coincide com teorias neoinstitucionais da "cultura global" desenvolvidas pela Escola de Stanford ${ }^{27}$, com conceitos de pluralismo jurídico global pós-modernos ${ }^{28}$, com teorias da regulação política ${ }^{29}$, com a economia política internacional ${ }^{30}$ e teorias da sociedade civil global ${ }^{11}$. Da mesma forma, os riscos para os espaços individuais e sociais autônomos são identificados ao impulso totalizador das organizações e das instituições sociais mundiais, das "redes transnacionais" e dos diversos sistemas globais, tais como o sistema econômico, o sistema político, o sistema religioso, o sistema científico, o sistema de saúde etc. Nenhum desses deuses sociais de barro admite outro deus diante deles ${ }^{32}$; todos perseguem um programa implacável de maximização de sua própria racionalidade. Segue-se que tal sociedade policontextual não permite que se identifique o indivíduo (no singular), pois a multiplicidade de homo-fórmulas indica os numerosos nexos entre os vários sistemas e o indivíduo: homo sapiens, homo faber, homo ecologicus, homo militans, homo economicus, homo politicus, homo sociologicus, homo religious, homo psychologicus etc. 33 .

As relações de exploração e subordinação entre indivíduos e sociedade surgem no contexto de sistemas funcionais específicos. Nancy Fraser 34 argumenta, por exemplo, que os indivíduos são "perpassados por uma multiplicidade de linhas de diferença e desigualdade que se entrecruzam". No pior dos casos, isso pode levar a situações em que nem mais a própria vida é algo que se possa perder35.É evidente que tais situações precárias, na medida em que resultam das estruturas do sistema econômico, podem resultar em conseqüências existenciais peculiares. As investigações de inspiração marxista tomam essa situação como ponto de partida. Ao sublinhar a função central do sistema econômico para as condições de reprodução social, as "teorias dos sistemas materialistas" 36 supõem a centralidade dos sistemas econômicos. Segundo essa perspectiva, a noção de "capitalismo" caracteriza não apenas o funcionamento do sistema econômico, mas uma formação sistêmica (histórica), uma situação específica de interdependência entre os sistemas político, econômico e jurídico no conjunto das instituições sociais mundiais. O sistema jurídico privado autônomo (direito) da posse de propriedade (economia), garantido pelo monopólio estatal da força (política), implica uma primazia "ecológica" do sistema econômico sobre seu ambiente social37. O "capitalismo" não é tanto um esquema de determinação nas relações entre base e superestrutura quanto um arranjo sistêmico específico em uma sociedade mundial diferenciada.

A teoria crítica dos sistemas não descreve apenas essas formações sociais mundiais, mas por força da maiêutica social também chama a
[27] Meyer e outros. "World Society and the Nation-State".American Journal of Sociology,1997,vol.103, pp.144ss.

[28] Santos, Boaventura de Sousa. Toward a new legal common sense: law, globalization and emancipation. Londres: Butterworths LexisNexis, 2002; e Hanschmann. "Theorie transnationaler Rechtsprozesse,". In: Buckel e outros (eds.). Neue Theorien des Rechts. Stuttgart: Lucius und Lucius, 2009, pp.375ss.

[29] Sassen, Saskia. Territory, authority, rights. Princeton, NJ: Princeton University Press, 2006, p. 224.

[30] Möller, op.cit.

[31] Brunkhorst. Solidarität. Frankfurt a.M.: Suhrkamp, 2002, pp. 274ss.

[32] Ver o conceito de politeísmo de Max Weber (Gesammelte Aufsätze zur Wissenschaftslehre. Tübingen: Mohr, 1968, p. 605) e a interpretação de Teubner ("Altera Pars Audiatur: Das Recht in der Kollision anderer Universalitätsansprüche". Archiv für Rechts- und Sozialphilosophie, 1996, Beiheft 65,pp.199-220).

[33] Fuchs, Peter. Der Eigen-Sinn des Bewußtseins. Bielefeld: Transcript, 2003, pp.16, 47.

[34] Fraser, Nancy. "Soziale Gerechtigkeit im Zeitalter der Identitätspolitik". In: Fraser e Honneth, A. (eds.). Umverteilung oder Anerkennung? Frankfurt a.M.: Suhrkamp, 2003, p. 80.

[35] Luhmann. "Inklusion und Exklusion". In: Die Soziologie und der Mensch: Soziologische Aufklärung. Opladen: Westdeutscher Verlag, 1995, vol. 6 .

[36] Sobre esse conceito, ver Brunkhorst. Kommentar zu Karl Marx: Der achtzehnte Brumaire des Louis Bonaparte. Frankfurt a.M.: Suhrkamp, 2007, p. 228.

[37] Jessop, op. cit.; ver também Schimank, Uwe. "Funktionale Differenzierung und gesellschaftsweiter Primat von Teilsystemen - offene Fragen bei Parsons und Luhmann". 
Soziale Systeme, 2005, vol. 11, pp. 395ss; e idem. "Die Moderne: eine funktional differenzierte kapitalistische Gesellschaft". In: Berliner Journal für Soziologie 2009, pp.327ss. Sobre as primeiras reflexões nessa direção, ver Luhmann. "Identitätsgebrauch in selbstsubstitutiven Ordnungen, besonders Gesellschaften" [1981]. In: Soziologische Aufklärung, op.cit., vol.3., p. 217.

[38] Teubner, "Der Umgang mit Rechtsparadoxien”, op. cit., p. 44.

[39] Fuller, Lon. The Morality Of Law. New Haven: Yale University Press, 1969; Selznick, Philip. Law, Society And Industrial Justice. Nova York: Russell Sage Foundation, 1969; Ewald, François. L'état Providence. Paris: B. Grasset, 1986; Friedland, Roger E Alford, Robert. "Bringing Society Back In: Symbols, Practices, And Institutional Contradictions". In: Powell, W. E Dimaggio, Paul (Eds.). The New Institutionalism In Organizational Analysis. Chicago, University Of Chicago Press, 1992.

[40] Teubner, "Der Umgang mit Rechtsparadoxien", op. cit., p. 43

[41] "Toda reificação é um esquecimento": Horkheimer, Max e Adorno. Dialektik der Aufklärung. In: Adorno, Gesammelte Schriften, op. cit., vol. 3, p. 263. Para o processo de invisibilização, ver Luhmann, Recht der Gesellschaft, op. cit., p. 221.

[42] Teubner, "Der Umgang mit Rechtsparadoxien”, op. cit., p. 42.

[43] Adorno. "Vorlesung über Negative Dialektik: Fragmente zur Vorlesung 1965/66". In: Nachgelassene Schriften. Frankfurt a.M.: Suhrkamp, 2003, vol.16, p. 16.

[44] Para a combinação de desconstrução e teoria dos sistemas, ver Menke. "Subjektive Rechte: Zur Paradoxie der Form". Zeitschrift für Rechtssoziologie, 2008, vol.29, pp. 81ss, p. 86 .

[45] Teubner, "Der Umgang mit Rechtsparadoxien", op. cit., p. 36 .

[46] Idem. "Selbstsubversive Gerechtigkeit: Kontingenz- oder Transzendenzformel des Rechts?". Zeitschrift für Rechtssoziologie, 2008, vol. 29, pp. 9-36, p. 26 atenção para a "liberação dos potenciais sociais normativos"38 para a socialização das instituições e, com isso, faz referência a um grande número de formulações da sociologia normativa a respeito das condições de possibilidade da justiça social em organizações, instituições e redes sociais 39 . Aqui, a teoria crítica dos sistemas da Escola de Frankfurt está preocupada com a proteção dos espaços sociais de liberdade, entendidos "como uma interdependência de autonomias parciais que dizem respeito à autonomia não somente dos sistemas funcionais, mas também dos indivíduos, das coletividades e das organizações. É uma concepção profundamente normativa" 4 .

\section{LIDANDO COM PARADOXOS}

\begin{abstract}
Quem não deseja ser ludibriado pela experiência da preponderância da estrutura sobre a matéria em questão, não desprezará, contrariando a maioria de seus oponentes, as contradições em favor da metodologia, considerando-as meros erros conceituais e despachando-as por meio da harmonia da sistemática científica.

Em vez disso, ele as realocará na estrutura que foi antagônica desde que surgiu pela primeira vez a sociedade organizada, e que permanece como tal...

Adorno, Gesammelte Schriften, vol. 8, p.357
\end{abstract}

Assim como a primeira geração da Teoria Crítica, a teoria crítica dos sistemas da Escola de Frankfurt considera as contradições reais o motor da sociedade. Os paradoxos não podem ser eliminados; no máximo, podem ser ocultados pelos discursos hegemônicos ${ }^{41}$. Contudo, isso exige que "sua latência permaneça latente, suas aporias sejam removidas, a desconstrução seja dispensada, a astúcia seja limitada, a crítica seja evitada, vendas sejam colocadas, e que se diga mentiras aos estudantes" 42.

Em vez de reproduzir acriticamente as contradições sociais ao negá-las e torná-las invisíveis, a explicitação dos paradoxos visa à desmistificação e à crítica imanente. $\mathrm{Na}$ tradição hegeliana, a dialética qua método significa pensar tanto em função de uma contradição como contra ela, contradizendo-a. "Uma contradição na realidade", segundo Adorno, "é uma contradição contra a realidade". É exatamente essa contradição que para Adorno tampouco pode ser superada pela síntese ${ }^{43}$; a teoria crítica dos sistemas aborda essa questão ao lidar conceitualmente com os paradoxos em todos os sistemas sociais (e não apenas no âmbito da política institucional) como um fenômeno genuinamente "político" 44: "O 'político' aparece então como tomada de decisão num contexto de indefinição que ultrapassa o sistema político, assim como a incomensurabilidade de sentido em arranjos antagônicos" 45 . Isso permite ver que, "apesar do monopólio estatal do uso da força, os processos de poder ocorrem além da política" ${ }^{46}$. 
A insistência da teoria dos sistemas com a onipresença do paradoxo como entrave à justificação das instituições sociais, em suas fundações místicas, por assim dizer, despertou críticas ${ }^{47}$. Esses ataques remetem a uma objeção que Jürgen Habermas48 já havia levantado: "Quem insiste em colocar o 'paradoxo' no lugar antes ocupado pela filosofia e suas fundamentações últimas, não apenas assume uma posição incômoda; ainda, essa posição só pode ser justificada caso se mostre que não há nenhuma outra saída". Essa frase, que hoje é dirigida contra a teoria dos sistemas, foi originalmente usada por Habermas contra Adorno e Horkheimer em $O$ discurso filosófico da modernidade, de 1985. Em seu argumento, Habermas substitui o paradoxo pelo conceito de intersubjetividade fundado em sua teoria do discurso, enquanto Horkheimer e Adorno não se permitiriam encontrar saída para essa desconfortável posição do paradoxo49.

Em relação a essa questão, a teoria crítica dos sistemas retorna às raízes da Teoria Crítica. Existem aqui pontos de contato com abordagens paradoxológicas na própria teoria crítica atual, que já estiveram presentes no Instituto de Pesquisa Socialso e que se concentraram em cisões, paradoxos e contradições sociais, na linha de Albrecht Wellmer" ${ }^{51}$ Tal como o projeto de Urs Staehelis de "atualizar Luhmann com Foucault" 52 , Christoph Menke embarcou em uma releitura francesa das relações sistêmicas de auto-reprodução. Ambos partem do colapso do "sentido" e interpretam os processos de auto-reflexão no direito como processos políticos, como uma disputa pela própria forma jurídica ${ }^{33}$. Também Antonio Negri54 saudou entusiasticamente esse interesse por antagonismos, paradoxos e incomensurabilidades em seus comentários recentes sobre a teoria jurídica dos sistemas de Teubner: "É de se admirar que sejam logo os doutores em direito os que dirigem o espírito da nova era contra as tradições filosóficas enfadonhas".

O problema dos paradoxos permanece para o caso do direito, que foi bastante desafiado pela teoria crítica dos sistemas, não sem conseqüências. Enquanto a primeira geração de teóricos críticos deu pouca atenção a questões do discurso jurídico, e especialistas em direito como Kirchheimer, Neumann e Abendroth tinham pouco acesso ao círculo interno presidido por Marcuse, Horkheimer e Adorno, a teoria crítica atual incorporou enfaticamente discursos jurídicos do âmbito nacional e internacional 55 . No entanto, em contraste com a teoria crítica dos sistemas, que revela o lado político do direito se referindo a seus fundamentos paradoxais, as segunda e terceira gerações da teoria crítica escolheram uma abordagem kantiana, abordando a política como se fosse uma "doutrina do direito aplicada" e procurando atualizar a idéia da democracia no contexto de uma sociedade globalizada. Nessa linha, Jürgen Habermas desenvolveu sua filosofia do direito em
[47] Ver Günther, Klaus. "Kopf oder Füße? Das Rechtsprojekt der Moderne und seine vermeintlichen Paradoxien". In: Kiesow e outros (eds.). Summa: Festschrift für Dieter Simon zum 70. Geburtstag. Frankfurt a.M.: Klostermann, 2005; Bung, Jochen. "Das Bett des Karneades: Zur Metakritik der Paradoxologie". In: Brugger, W. e outros (eds.). Rechtsphilosophie im 21. Jahrhundert. Frankfurt a.M.: Suhrkamp, 2008.

[48] Habermas, Jürgen. Der philosophische Diskurs der Moderne. Frankfurt a.M.: Suhrkamp, 1985, p. 155.

[49] Demirović, op.cit., p. 523.

[50] Ver Honneth. "Organisierte Selbstverwirklichung: Paradoxien der Individualisierung". In:Honneth (ed.). Befreiung ausderMündigkeit:Paradoxien des gegenwärtigen Kapitalismus. Frankfurt a.M.: Campus, 2002; Hartmann, Martin. "Widersprüche, Ambivalenzen, Paradoxien: Begriffliche Wandlungen in der neueren Gesellschaftstheorie". In: Buckel e outros (eds.), op. cit.

[51] Wellmer, Albrecht. Endspiele: Die unversöhnlicheModerne. Frankfurt a.M.: Suhrkamp, 1993; Seel, Martin. Paradoxien der Erfüllung. Frankfurt a.M.: Fischer, 2006; Menke, "Subjektive Rechte: Zur Paradoxie der Form", op.cit., pp. 81ss.

[52] Staeheli, Urs. "Updating Luhmann mit Foucault?". kultuRRevolution: Zeitschrift für angewandte Diskurstheorie, vol.47, 2004, pp.14ss; Fischer-Lescano, Andreas e Christensen, Ralph. "Auctoritatis interpositio: Die Dekonstruktion des Dezisionismus durch die Systemtheorie". Der Staat, 2005, pp. 213 ss.

[53] Cf.Menke, "Subjektive Rechte", op. cit., p. 86. O paradoxo do direito torna-se aparente, uma vez que cria $\mathrm{e}$ questiona a forma dos "direitos subjetivos", ao revelar o "caráter essencialmente político do direito autoreflexivo". Ver também Staeheli, op. cit.; Fischer-Lescano e Ralph, op. cit.

[54] Negri, op.cit., p.11.

[55] Sobre a segunda geração da teoria crítica e do direito, ver Niesen, Peter e Eberl. "Demokratischer Positivismus: Habermas/Maus". In: Buckel e outros, op. cit. 
[56] Habermas. Faktizität und Geltung. Frankfurt a.M.: Suhrkamp, 1992.

[57] Idem. "Eine politische Verfassung für die pluralistische Weltgesellschaft?". Kritische Justiz, 2005 pp. 222ss. Uma aplicação frutífera no campo da política internacional encontra-se em Deitelhoff, Nicole. Überzeugung in der Politik. Frankfurt a.M.: Suhrkamp, 2006.

[58] Maus. Zur Aufklärung der Demokratietheorie: Rechts- und demokratietheoretische Überlegungen im Anschluß an Kant. Frankfurt a.M.: Suhrkamp, 1992; idem, "Das Verhältnis der Politikwissenschaft zur Rechtswissenschaft: Bemerkungen zu den Folgen politologischer Autarkie". In: Becker, M. e Zimmerling (eds.). Politik und Recht. Wiesbaden: VS, 2006. São instrutivas as análises de Eberl, Oliver. Demokratie und Frieden: Kants Friedensschrift in den Kontroversen der Gegenwart. BadenBaden: Nomos, 2008.

[59] Brunkhorst. "Die Legitimationskrise der Weltgesellschaft: Global Rule of Law, Global Constitutionalism und Weltstaatlichkeit". In:Albert, M.e Stichweh, R. Weltstaat und Weltstaatlichkeit. Wiesbaden: VS, 2007 .

[6o] Günther, Klaus. Der Sinn für Angemessenheit. Frankfurt a.M.: Suhrkamp, 1988; Günther e Randeria, Shalini. Recht, Kultur und Gesellschaft im Prozeß der Globalisierung. Bad Homburg: Werner Reimers Stiftung, 2001; e Frankenberg, Günter."Zivilgesellschaft im transnationalen Kontext". Maecenata Jahrbuch für Philanthropie und Zivilgesellschaft, 2003, pp. 13ss; Ibidem. Autorität und Integration: Zur Grammatik von Recht und Verfassung. Frankfurt a.M.: Suhrkamp.

[61] Para uma visão de conjunto, ver Frankenberg. "Partisanen der Rechtskritik: Critical Legal Studies". In: Buckel e outros, op. cit.

[62] Horkheimer e Adorno, op. cit., p. 263.

[63] Derrida, Jacques. "Force of law: the mystical foundation of authority". In: Cornell, D.e outros (eds.).Deconstruction $\mathcal{E}$ the possibility of justice. Nova York: Routledge, 1992.
Facticidade e validade $5^{6}$ e se ocupou intensamente com o direito internacional em estudos mais recentes 57 . Sob a influência de Rousseau, Ingeborg Maus $5^{8}$ enfatiza a necessidade de um estudo abrangente dos processos políticos e jurídicos na sociedade mundial. Também Hauke Brunkhorst 59 chama a atenção para a interdependência dos processos políticos e jurídicos na sociedade mundial. A teoria crítica no campo do direito torna-se explícita especialmente nos trabalhos de Klaus Günther e Günter Frankenberg ${ }^{60}$; este último combina ao mesmo tempo uma teoria crítica do direito da Escola de Frankfurt com estudos dos critical legal studies (crits) desenvolvidos por Duncan Kennedy, David Kennedy, Martti Koskenniemi e Anthony Anghie e outros ${ }^{61}$.

Todas essas abordagens situam o direito em seu contexto social e, por isso, evitam a descontextualização dogmática ${ }^{62}$. Mais do que a Teoria Crítica do direito da Escola de Frankfurt, os crits enfatizam a indeterminação do direito fazendo referência ao realismo jurídico e afiam suas críticas nos esquemas de aporias de Derrida ${ }^{63}$. Apesar de todas as diferenças, tais trabalhos têm em comum o fato de considerarem a política e o direito em estreita relação $0^{64}$. A teoria crítica sistêmica do direito preocupa-se especialmente em revelar o caráter contraditório da presença da política no direito. Esse ponto já foi destacado por Marx: "Existe, portanto, uma antinomia, direito contra direito, ambos portando igualmente a marca da lei da troca"65.

\section{A JUSTIÇA COMO UMA FÓRMULA CONTINGENTE E TRANSCENDENTE}

\section{Odireito é a manifestação primordial da racionalidade irracional. \\ Adorno.Negative Dialektik, p.303; "Individuum und Organisation", p. 445}

Adorno criticou insistentemente a consistência e a totalidade como ideais burgueses de necessidade e universalidade ${ }^{66}$. O "fechamento sistêmico" foi atacado por ele por tornar herméticas, por razões metodológicas, as questões em jogo e por exercer o papel de autojustificação dos sistemas contra a "ubiqüidade do mercado". Isso coincide com a descrição que a teoria dos sistemas fornece do desenvolvimento da "ordem a partir do ruído", na co-evolução de sistema e do ambiente ${ }^{67}$. Tanto Adorno como a teoria crítica dos sistemas não concebemo "sistema" como uma hierarquia estrutural estática. Tal noção, duramente denunciada por Friedrich Nietzsche $e^{68}$, é estranha a ambas as abordagens sistêmicas. Na verdade, ambos descrevem a autonomização dinâmica, progressiva e eruptiva das racionalidades como um processo dialético de emergência de sistemas auto-referentes. A problemática da autonomização foi resumida por Adorno em sua filosofia da música; ele faz a acusação de que a música solipsista, com sua textura rígida, que permi- 
te a ela se preservar contra a ubiqüidade das operações, tornou-se tão severa que seu elemento transcendente e real - que chegou a dar-lhe o conteúdo que fez a música absoluta verdadeiramente absoluta - é inalcançável ${ }^{69}$. O ponto crucial, segundo argumenta Adorno em sua Teoria estética, está no fato de a instituição social existir apenas em sua relação com aquilo que ela não é, com seu outro ${ }^{70}$, assim como precisar se manter aberta às influências externas. Fechamento e abertura, simultaneamente: quem está aberto para todas as coisas se torna vazado; ao mesmo tempo, o autismo sistêmico precisa ser evitado. Essas reflexões de Adorno sobre a arte valem, do ponto de vista da teoria dos sistemas, para um sem-número de áreas autopoiéticas de racionalidade, uma vez que todas existem apenas em sua relação com o ambiente social. Trata-se de estabelecer distinções ${ }^{71}$. As áreas reificadas de racionalidade como realidades sociais (arte, economia, política, direito etc.) não são enquanto entidades ontológicas, mas construções dessa mesma sociedade; no jargão da crítica da ideologia, são ficções, aparências, deuses sociais. Contudo, Adorno também insistiu que as noções fetichizadas não são apenas aparências: quando os seres humanos realmente se tornam viciados nessas objetividades opacas, as reificações não aparecem somente como falsa consciência, mas simultaneamente como realidade. No momento em que as categorias da aparência também são categorias da realidade, a dialética se torna manifesta ${ }^{72}$.

A teoria crítica dos sistemas da Escola de Frankfurt procura associar à ordem social fechada a necessidade prática do desenvolvimento de uma teoria da acumulação ${ }^{73}$ com o objetivo de ligar novamente as esferas autônomas de racionalidade à realidade sem a qual aquelas não poderiam existir. A questão central que devemos nos colocar daqui em diante é: "Em que esferas sociais são desenvolvidas as utopias sociais?"74. Essa questão atinge o cerne do problema da justiça. Ao respondê-la, a teoria crítica dos sistemas demanda "uma justiça que seja capaz de subverter a si mesma, formulada de maneira contingente e transcendente". Isso nos leva a um duplo conceito de justiça, que, como fórmula contingente intra-sistêmica, precisa preservar tanto sua consistência interna como sua permeabilidade em relação às demandas vindas da sociedade 75 . As implicações normativas dessa fórmula, coerente com a própria auto-representação da esfera jurídica, não devem ser subestimadas, pois obrigam o direito a buscar traduzir os conflitos estruturais da sociedade em quaestio iuris, a manter mutuamente compatíveis os espaços de autonomia, a garantir as condições para a autoconstituição dos indivíduos. Contudo, o modelo normativo de justiça como fórmula contingente e transcendente excede essa interpretação. Uma visão que insistisse na fórmula contingente e tentasse universalizá-la apenas provocaria nova injustiça. É exa-
[64] Para uma análise geral dos pensadores jurídicos na teoria crítica, ver Perels, Joachim. "Kritische Justiz und Frankfurter Schule". In: Claussen, Detlef e outros (eds.). Philosophie und Empirie. Frankfurt a.M.: Hannoversche Schriften 4, 2001. Ver também a reconstrução sugerida em Buckel, Subjektivierung und Kohäsion, op. cit., pp. 8oss.

[65] Marx, Capital, op. cit., cap. 10, seção 1.

[66] Adorno. Minima Moralia. In: Gesammelte Schriften, op. cit., vol 4, p. 172.

[67] Luhmann. Die Gesellschaft der Gesellschaft. Frankfurt a.M.: Suhrkamp, 1998, pp. 789 ss.

[68] "A vontade do sistema é uma vontade de falta de integridade" (Nietzsche, Friedrich. Götzendämmerung [1888]. In: Das Hauptwerk: Werke, 1990, vol.4, p. 260, n. 26).

[69] Adorno. Philosophie der neuen Musik. In: Gesammelte Schriften, op. cit., p. 27.

[7o] Idem, Ästhetische Theorie. In: Gesammelte Schriften, op.cit.,, vol.7, p.12.

[71] "Estabelecer uma distinção: a fonte teórica decisiva para uma investigação da teoria dos sistemas é a distinção entre sistema e ambiente" (Luhmann, Die Gesellschaft der Gesellschaft, op. cit., p. 60).

[72] Adorno, "Über Marx und die Grundbegriffe der soziologischen Theorie. Seminarmitschriften", op. cit., p. 508 .

[73] Teubner e Zumbansen, Peer. "Rechtsentfremdungen: Zum gesellschaftlichen Mehrwert des zwölften Kamels". Zeitschrift für Rechtssoziologie, 2000, vol. 21, pp.189-215.

[74] Teubner, "Der Umgang mit Rechtsparadoxien", op. cit., p. 37.

[75] Fögen, Marie Theres. Das Lied vom Gesetz. München: Carl-Friedrich-von-Siemens-Stiftung, 2006 , pp. 95 ss. 
[76] "Um excesso de justiça pode ser causa de grande injustiça". Ver Teubner, "Selbstsubversive Gerechtigkeit", op. cit., p.33.

[77] Cf. Kleist, Heinrich von. Michael Kohlhaas [1810.].München:DTV,1997.

[78] Ibidem, p. 28; ver também Idem. "Ökonomie der Gabe - Positivität der Gerechtigkeit: Gegenseitige Heimsuchungen von System und différance". In: Koschorke, A. e Vismann, C. (eds.). System - Macht - Kultur: Probleme der Systemtheorie. Berlim: Akademie, 1999, pp. 199-212.

[79] Fischer-Lescano. "Global constitutional struggles: human rights between colère publique and colère politique". In: Kaleck, W. e outros (eds.). International prosecution of human rights crimes. Berlim: Springer, 2006.

[8o] Adorno.Negative Dialektik.In:Gesammelte Schriften, op.cit.,vol. 6, p. 281.

[81] Ver também Bonacker, Thorsten. Die normative Kraft der Kontingenz: Nichtessentialistische Gesellschaftskritik nach Weber und Adorno. Frankfurt a.M.: Campus, 2000, pp. 273ss.

[82] Buckel."Zwischen Schutz und Maskerade: Kritik(en) des Rechts". In: DemiroviĐ (ed.). Kritik und Materialität.Münster:Westfälisches Dampfboot, 2008, pp.110ss.

[83] Baseado nessa diferença, Christoph Menke ("Subjektive Rechte", op. cit., p. 107) desenvolveu um conceito "político" de direitos subjetivos, que se refere à noção de um direito a ter direitos e, por isso, à noção de direitos humanos.

[84] Sobre a dialética negativa como uma "justiça restauradora", ver Honneth, Pathologien der Vernunft: Geschichte und Gegenwart der Kritischen Theorie, Frankfurt a.M.: Suhrkamp, 2007.

[85] Adorno, Negative Dialektik, op. cit., p. 150.

[86] Horkheimer. Kritische Theorie der Gesellschaft, 1968, vol. 2, p. 304 ver também idem, "Traditionelle und kritische Theorie". Zeitschrift für Sozialforschung, 1937, vol. 6, pp. 245 ss. tamente desse imperialismo da racionalidade jurídica que a teoria crítica dos sistemas acusa as teorias universalistas da justiça. Ele pode ser muito perigoso porque implica summum ius summa inju$r^{1}{ }^{76}$. Essa conseqüência kohlhaasiana77 da imanência reificada do direito é combatida pela teoria crítica dos sistemas com o elemento transcendente. Ela exige (normativamente) a abertura a uma "referência adicional" (Verweisungsüberschusses), à ativação de energias utópicas sob a precondição de injustiças realmente vividas. Isso significa "a exigência de transcendência para transformar a imanência em algo que lheé estranho [...]. A justiça torna-se manifesta apenas por meio de uma passagem real pela injustiça" 78 .

Processos sociais de colère publique79 são formas de articulação da experiência de injustiça, que Adorno já havia mencionado ao tratar do fenômeno da imediaticidade social e ao solidarizar-se com aqueles "corpos atormentados" (para usar a expressão de Brecht), um indício de que o indivisível apenas existe em casos extremos, na reação espontânea de quem impacientemente não pode mais tolerar os argumentos sustentados pelo terror ${ }^{80}$. Adorno e a teoria crítica dos sistemas estão unidos em sua acusação contra a ciência administrativa da justiça. A imediaticidade social existe somente em configurações que não transformam a justiça em organizações jurídicas. Ao mesmo tempo, e aqui se nota seu momento dialético, a condição para que a fórmula transcendente tenha efeito é que a operação estabelecida e praticada pelo direito exista no mundo ${ }^{81}$. É exatamente essa interdependência mútua de "proteção e farsa" 82 , de imanência e transcendência ${ }^{83}$, de que trata Adorno, em relação à troca de bens, na Dialética Negativa ${ }^{84}$ :

Se simplesmente se anula a categoria de medida da comparabilidade, então o que entraria no lugar da racionalidade, que era realmente ideológica e também inerente ao princípio de troca como se fosse uma promessa, é a expropriação imediata, violência, nos dias de hoje: o puro privilégio dos monopólios e das facções. O que a crítica ao princípio de troca [...] deseja é que o ideal da troca livre e justa, até hoje um mero pretexto, se torne realidade. Apenas isso transcenderia a troca ${ }^{85}$.

\section{CRÍTICA IMANENTE COMO UMA ATITUDE DE TRANSCENDÊNCIA}

Uma certa maneira de pensar, falar, fazer, uma certa relação com o que existe, com o que se conhece, com o que se faz, uma relação com a sociedade, cultura, uma relação com os outros também - algo que poderíamos chamar de atitude crítica.

Foucault. Was ist Kritik?, 1992, p.8

Para Horkheimer ${ }^{86}$ a verdadeira função social da filosofia é a crítica do status quo. Assumindo seriamente esse ponto de partida, a 
teoria crítica dos sistemas não é meramente tecnologia social, nem descrição sociológica extrínseca, nem autodescrição teórico-jurídica, mas um esforço eminentemente filosófico de crítica social. Para tal projeto de crítica, não há ponto fixo fora da sociedade; na verdade, a crítica tem de começar pelo referencial transcendente que transborda da própria imanência. É no arcanum da sociedade, na atitude, no ponto de vista e na resistência que "a faculdade de distinguir o reconhecível e o meramente convencional, ou o que está sob a coerção da autoridade vigente, [...] [surge] como crítica, que é derivada do termo grego krino, decidir"87. Uma vez que não existe um sujeito que paira por sobre a sociedade, não há posição disponível fora da sociedade a partir da qual as coisas possam ser claramente descritas; a alavanca da crítica, portanto, tem de se apoiar nas nossas próprias discrepâncias ${ }^{88}$.

A crítica da teoria crítica dos sistemas toma o direito de sociedades reais como ponto de partida. Em contraste com a perspectiva hierarquizante e totalizante do direito racional moderno (Vernunftrecht, Kant) e também com a crítica imanente do pensamento em totalidades (Kierkgaard), a teoria crítica dos sistemas da Escola de Frankfurt não se preocupa em repensar o "direito na diferença" (em oposição à razão) ou a "diferença no processo de decisão jurídica", mas em radicalizar a intenção de decifrar a produção da forma como política e, desse modo, tematizar as contradições fundamentais da sociedade. Tal empreendimento pode ser levado adiante - e nesse ponto as análises da teoria dos sistemas se ligam à abordagem de Christoph Menke - se a luta em torno das formas jurídicas for observada de modo desconstrutivo; normativamente, não é apenas o pano de fundo para a explicitação de expectativas não realizadas, mas também a justificação do direito pelo próprio antagonismo que lheé próprio. A diferença entre a forma e a produção da forma, entre forma e poder, é um aspecto da normatividade: "O poder, de cuja expansão emerge a forma, é ao mesmo tempo uma exigência que se volta contra a própria forma que emerge. Essa exigência requer que a forma corresponda ao seu outro, que lhe faça justiça" 89 .

A teoria crítica dos sistemas integra en sua crítica do direito essas exigências normativas que no direito se voltam contra o próprio direito de forma paradoxal e o leva a transcender a si mesmo num permanente tornar-se justiça do outro. Em sua busca por justiça, a teoria crítica dos sistemas argumenta com e por meio do direito e se submete às constrições sistêmicas de sentido para logo livrar-se delas e contribuir para "quebrar o encanto" do fechamento sistêmico90. Nesse sentido, a teoria crítica dos sistemas explorou, em vários estudos, a possibilidade de uma ciência jurídica socialmente adequada e sociologicamente informada. Ela acrescentou uma pers-
[87] Adorno. "Kritik".In:Gesammelte Schriften, op. cit., vol.10, p. 785 .

[88] Idem. "Spätkapitalismus oder Industriegesellschaft". In: Gesammelte Schriften, op. cit., vol. 8, p. 369 . Sobre as similitudes entre Luhmann e Adorno, ver Breuer. Die Gesellschaft des Verschwindens. Hamburg: Rotbuch-Verlag, 1995, pp. 65ss; Brunkhorst. "Die ästhetische Konstruktion der Moderne: Adorno, Gadamer, Luhmann". Leviathan, 1988 , pp. 77ss; Wagner, Elke. "Gesellschaftskritik und soziologische Aufklärung: Konvergenzen und Divergenzen zwischen Adorno und Luhmann". Berliner Journal für Soziologie, 2005, pp.37ss.

[89] Menke, "Subjektive Rechte", op. cit., p. 105.

[9o] Adorno, Negative Dialektik, op. cit., p.369. 
[91] Teubner. Netzwerk als Vertragsverbund. Baden-Baden: Nomos, 2004; ver também Vesting, Thomas. Rechtstheorie. München: Beck, 2007, pp. 67ss.

[92] Fischer-Lescano e Teubner. Regime-Kollisionen. Frankfurt a.M.: Suhrkamp, 2006.

[93] Teubner e Fischer-Lescano. “Cannibalizing Epistemes:Will Modern Law Protect Traditional Cultural Expressions?". In: Graber, Ch. e Burri-Nenova, M. (eds.). Traditional cultural expressions in a digital environment. Cheltenham: Elgar, 2008 , pp.17ss.

[94] Teubner, "Die anonyme Matrix", op. cit., p. 45.

[95] Fischer-Lescano. "Kritik der praktischen Konkordanz". Kritische Justiz, 2008, pp. 166ss; ver também Ladeur, Karl-Heinz. Kritik der Abwägung. Tübingen: Mohr, 2004, pp. 9ss.

[96] Adorno. Minima Moralia, op. cit., p. 55 .

[97] "In nuce - a tarefa da arte atualmente é trazer o caos à ordem". Sobre esse exemplo, ver Teubner, "Selbstsubversive Gerechtigkeit", op. cit., pp. 23, 31; e Wiethölter. "Zur Argumentation im Recht: Entscheidungsfolgen als Rechtsgründe?". In: Teubner (ed.). Entscheidungsfolgen als Rechtsgründe. Baden-Baden: Nomos, 1994, p. 107.

[98] Adorno, Minima Moralia, op. cit., p. 143.

[99] Adorno. Erziehung zur Mündigkeit. Frankfurt a.M.: Suhrkamp, 1971, p. 137.

[100] "Nada me parece mais ultrapassado do que o clássico ideal emancipatório" (Derrida, "Force of law", op. cit., p. 28).

[101] Adorno. "Philosophie und Lehrer" [1962]. In: Erziehung zur Mündigkeit, op. cit., p. 43 .

[102] Adorno, Gesammelte Schriften, op. cit., p. 144 . pectiva jurídica sobre as redes ${ }^{91}$, colisões de regimes ${ }^{92}$, princípios organizacionais sociais colidentes ${ }^{93} \mathrm{e}$ redes transnacionais 94.

Dois aspectos da crítica me parecem significativos para o direito: (1) crítica dos valores: a reformulação jurídica dos conflitos sociais em torno da estrutura social e de questões distributivas em termos de construções sofisticadas de valores e princípios, sobre os quais se poderia chegar a um acordo prático, consiste na tentativa inadequada e de caráter autoritário de solucionar os conflitos sociais do século XXI com base na fórmula de Graciano do século XII. Esse método torna as lutas sociais por intermédio do direito irreconhecíveis; ele precisa ser substituído, principalmente pela criação das precondições para a segurança mútua de espaços de autonomia e por meio de "liberdades sob condições" experimentais, que possibilitariam a auto-regulação social - como, por exemplo, aquela realizada na autonomia tarifária95. (2) Crítica ao estatismo: não é mais apenas a política que usurpa os espaços sociais de autonomia. Amplos sistemas sociais - e aqui a teoria crítica dos sistemas se une à tese de Habermas da "colonização do mundo da vida" - implicam riscos específicos, que precisam ser combatidos pela introdução da obrigação de se agir de modo responsável em relação ao ambiente social (seres humanos, sistemas, ecossistema natural).

A crítica dos valores e do estatismo traduz a teoria crítica dos sistemas para contra-modelos concretos com os quais pode intervir nas lutas pela adequação social das leis existentes. Uma vez que o todo é o não verdadeiro96, quem quer introduzir o "caos na ordem" - como diz Teubner 97 em referência a Adorno ${ }^{8}$ - precisa forçar o sistema de dentro para fora para com isso "jogar a faísca nessa lareira que pode fazê-la explodir"99.

\section{O IDEAL EMANCIPATÓRIO EM UMA “ASSOCIAÇÃO DE HOMENS LIVRES"}

Imaginemos, finalmente, uma associação de homens livres. Marx.Capital, 1867, cap. 1, seção 4

O lado desconstrutivo da teoria crítica dos sistemas explora as condições de realização do ideal emancipatório clássico ${ }^{100}$ e se volta à questão de saber se a maturidade, como ausência de relações reificadas - o que para Adorno não era um desenvolvimento natural, mas sim produto do desenvolvimento histórico ${ }^{101}-$ é ainda possível. $\mathrm{O}$ ponto de partida desse esforço reside no fato de as instituições sociais em que vivemos ainda serem heterônomas, ou seja, no fato de que "nenhum ser humano na sociedade vigente pode realmente existir de acordo com sua autodeterminação"102. 
Para conseguir uma solução para esse problema, não se deve "inflar as vacas para conseguir mais leite"103; portanto, não se pode confiar ao sistema político mundial a questão da sociedade mundial, como se tudo pudesse se resolver em um "mundo republicanizado". A política como sistema, esse fetiche da coletivização, é ópio para o povo, e equivale à institucionalização de uma fantasmagoria e uma declaração irrealizável de auto-suficiência. Em vez disso, a utopia é uma sociedade civil (jurídica) mundial sem o Estado. Pax bukovina em vez de pax americana $^{104}$. Associação de homens livres.

Esse ponto resulta em um número de exigências concretas, cujo objetivo é revelar, em uma perspectiva crítico-emancipatória, o núcleo normativo das instituições e das práticas realmente existentes, intervir na luta em torno da magnae chartae em relação às matrizes transnacionais e desenvolver em cada caso direitos humanos e organizacionais específicos. Diferentemente do modelo da co-evolução dos direitos humanos e dos direitos políticos de participação, a teoria crítica dos sistemas não está preocupada com modelos procedimentais de justificação que investigam abstratamente as condições de consenso universal em torno das normas; ela não está interessada na implementação de noções substantivas de justiça derivadas de ficções criadas de modo elitista e decisionista ${ }^{105}$, mas preocupada com a estabilização de uma resistência normativa in práxis ${ }^{106}$. Ao generalizar e re-especificar a função da constituição como uma conquista evolucionária, a teoria crítica dos sistemas entendequeos processos sociais de constitucionalização precisam ser assegurados, estabilizados e tornados permanentes. Sua preocupação principal é garantir que as instituições sejam permeáveis às demandas sociais ${ }^{107}$, seja por meio da obrigação imediata dos atores privados em relação aos direitos humanos e fundamentais ${ }^{108}$, seja por meio da obrigação em face dos direitos ambientais ${ }^{109}$ e dos direitos dos animais ${ }^{110}$, seja diante dos direitos institucionais no sentido ridderiano ${ }^{111}$ da proteção de espaços transpessoais de liberdade ${ }^{112}$.

Além desses direitos multidirecionais à proteção, aos benefícios e ao acesso que obrigam as autoridades privadas e públicas à solidariedade ${ }^{113}$, o próprio processo de criação do direito precisa ser socializado, não apenas por meio da humanização paternalista das instituições políticas que atribuem direitos de aclamação não-judiciais às ONGse que aliena seu papel legitimador em call centers de governança global à função de reduzir a resistência, mas principalmente por meio da alocação original de justificações jurídicas e direitos à ação ${ }^{114}$. Ou seja, a legislação da sociedade civil via escandalização; a vinculação de discussão e decisão em situações deliberativas por meio do estabelecimento coercitivo e legalmente estruturado de ligações entre es paços heterárquicos e policêntricos, privados e públicos, de ação organizacional e espontânea; a volta da deliberação nos processos de auto-regulação
[103] Luhmann. Politik der Gesellschaft. Frankfurt a.M.: Suhrkamp, 1999, p. 215.

[104] Teubner. "Globale Bukowina: Zur Emergenz eines transnationalen Rechtspluralismus". Rechtshistorisches Journal, 1996, vol. 15, pp. 255-90.

[105] Ver a crítica de Maus a Rawls e Habermas, em Maus. "Freiheitsrechte und Volkssouveränität". Rechtstheorie, 1995, vol. 26, pp.507ss.

[106] Teubner."DieErblast".Zeitschrift fürRechtssoziologie, 2008, pp.3-7, p.3.

[107] Para o significado da fórmula subjetivada do direito nesse contexto, ver Menke, "Subjektive Rechte", op. cit., pp. 81ss.

[108] Teubner, "Die anonyme Matrix",op.cit.

[109] Teubner e Fischer-Lescano, op. it.

[110] Teubner. "Elektronische Agenten und große Menschenaffen: Zur Ausweitung des Akteursstatus in Recht und Politik". Zeitschrift für Rechtssoziologie, 2006, vol. 27, pp. 5-30.

[111] Ladeur, Karl-Heinz. "Helmut Ridders Konzeption der Meinungsund Pressefreiheit in der Demokratie". Kritische Justiz, 1999, pp. 281ss.

[112] Fischer-Lescano e Christensen. Das Ganze des Rechts. Berlim:Duncker und Humblot, 2007, pp. 287 ss.

[113] Para o conceito de economia solidária, ver DemiroviĐ, Demokratie in der Wirtschaft, op. cit., pp. 273 ss.

[114] Ver Wiethölter. "Recht-Fertigungen eines Gesellschafts-Rechts". In: Joerges e Teubner (eds.), op. cit., pp.13ss. 
[115] Teubner. "Fragmented foundations: societal constitutionalism beyond the nation State". In: Dobner, P. e Loughlin, M. (eds.). The twilight of constitutional law, no prelo.

[116] Adorno, Philosophie der neuen Musik, op. cit., p. 169; ver também Horkheimer e Adorno. Dialektik der Aufklärung, op. cit. Em relação e este último ponto, ver Gebauer, Gunter e Wulf, Christoph.Mimesis. Reinbek bei Hamburg: Rowohlt \& Wulf, 1992, pp. 389 ss; e Metscher, Thomas. Mimesis. Bielefeld:Transcript, 2004, pp. 17ss.

[117] Marcuse, Herbert. Kunst und Befreiung. Lüneburg: zu Klampen, 200o, p. 138 .

[118] Adorno, Philosophie der neuen Musik, op. cit., p. 86.

[119] Weiss, Peter.Die Ästhetik des Widerstands. Frankfurt a.M.: Suhrkamp, 1978-1981, vols. 1-3.

[120] Teubner. "Was kommt nach dem Staat?". In: Giuliani, L. (ed.). Köpfe und Ideen. Berlim: Wissenschaftskolleg, 2008, p. 40; ver também Teubner. Organisationsdemokratie und Verbandsverfassung. Tübingen: Mohr/Siebeck, 1978.

[121] Fischer-Lescano e Teubner, Regime-Kollisionen, op. cit., pp. 53ss.

[122]Teubner. "Selbstsubversive Gerechtigkeit", op.cit., p. 21.

Recebido para publicação

em 15 de dezembro de 2009.

\section{NOVOS ESTUDOS}

CEBRAP

86 , março 2010

pp. 163-177 social. Em suma: trata-se da abertura das decisões estruturais da sociedade sobre processos democráticos por meio do desenvolvimento de direitos constitucionais da sociedade mundial, que liberta o potencial da sociedade civil global para a salvaguarda da autonomia ${ }^{115}$.

A principal preocupação da teoria crítica dos sistemas é a regeneração das relações autônomas na sociedade mundial, procurando romper com os padrões de estratificação das instituições sociais. A noção, desenvolvida pela teoria dos sistemas, de que os sistemas sociais estão obrigados a se responsabilizar socialmente encontra paralelos com o conceito de mimese na Teoria Crítica. Contudo, esse conceito se radicaliza na medida em que se exige que as condições têm de ser estabelecidas de modo que não apenas o sistema da arte trabalhe como um "corpo mimético" 116 . Antes, as ordens mundiais dos sistemas sociais precisam adotar uma relação mimética com a realidade externa ao sistema. "Deixar a transcendência aparecer na realidade, ou seja, a negação do existente na mimese do existente" ${ }^{117}$ não é assim apenas tarefa da arte, mas de todos os sistemas sociais que têm de ser orientados de modo que "o sujeito, em diferentes níveis de sua autonomia, possa [colocar-se] no outro, separado, mas também sem separar-se" 118 .

O cultivo da Estética da resistência ${ }^{119}$ não é, se podemos assim resumir a teoria crítica dos sistemas, uma característica exclusiva do sistema artístico; antes, trata-se de assegurar as práticas de resistência em esferas sociais normativas, preservando espaços de liberdade e espontaneidade e garantindo que prevaleçam sempre noções democráticas de organização, instituições, grupos e redes sociais ${ }^{120}$. A democratização e a garantia da responsabilização social das instituições sociais na economia, no direito, na religião etc. são o programa ${ }^{121}$ cuja existência continuada as instituições vigentes e ativas hoje não podem garantir. Diante das supostas tendências de autocontinuação bem ordenada da sociedade pós-moderna, a teoria crítica dos sistemas da Escola de Frankfurt, assim como a teoria crítica,

[...] fazem uso de sua preferência pela desordem, revolta, desvio, variação e mudança. Ela protesta em nome da sociedade, dos seres humanos e da natureza - mas assim ofaz [...] fora de seu arcanum interior. A justiça subversivaéo espinho em [sua] carne. O grande motim - essaésua mensagem ${ }^{122}$.

ANDREAS FISCHER-LESCANO é professor titular da cátedra de Direito Público, Europeu e Internacional e de Teoria do Direito, da Universidade de Bremen. É também diretor do Centro Europeu de Direito e Política. 